\title{
Instituto de Educação do Estado da Guanabara: pioneirismo e formação para o audiovisual educativo $(1960-1975)^{1}$
}

Institute of Education of the State of Guanabara: pioneering and training for the educational audiovisual (1960-1975)

Instituto de Educación del Estado de Guanabara: pionerismo y formación para el audiovisual educativo (1960-1975)

\author{
Cíntia Nascimento de Oliveira Conceição \\ Pontifícia Universidade Católica do Rio de Janeiro (Brasil) \\ http://lattes.cnpq.br/8675611493301310 \\ https://orcid.org/0000-0002-6101-6837 \\ cintiadeoliveira@yahoo.com.br
}

\section{Resumo}

O objetivo do artigo é analisar o circuito de Televisão Educativa do Instituto de Educação do Estado da Guanabara, destacando a centralidade do professor como produtor de conteúdo para televisão, atuante na concretização de um ideal de audiovisual educativo que atendesse as expectativas da sociedade no âmbito cultural, político e econômico. A formação para a televisão educativa sinalizou caminhos para a criação de uma didática própria para os audiovisuais educativos atenderem a uma demanda crescente de escolarização que ocorreu com a expansão da educação em consonância com ideais democráticos liberais para a construção de um Brasil "moderno". Para a realização da pesquisa trabalhamos com diferentes tipos de arquivos como: documentos de arquivos pessoais, periódicos da Hemeroteca Digital Brasileira e o acervo do Centro de Memória Institucional do Instituto de Educação - CEMI.

Palavras-chave: Audiovisual educativo. Formação de professores. Teleducação.

\footnotetext{
${ }^{1}$ Esse artigo é uma versão diferente da anteriormente publicada na forma de capítulo no livro PIMENTA, Jussara; PACÍFICO, Juracy; MONTEIRO, Filomena; BUENO, José. Docência, Formação e Práticas Pedagógicas: Experiências e Pesquisas. Jundiaí (SP): Paco, 2019. Embora abordem a mesma temática, eles se diferem no destaque dado ao professor como produtor de conteúdo para televisão educativa.
} 


\begin{abstract}
The purpose of this article is to analyze the circuit of Educational Television of the State Education Institute of Guanabara, highlighting the centrality of the teacher as producer of television content, acting in the realization of an ideal audiovisual educational that meets the expectations of society in the cultural sphere, Political and economic. The training for educational television signaled ways for the creation of a didactic for the educational audiovisuals to attend to a growing demand for schooling that occurred with the expansion of education in line with liberal democratic ideals for the construction of a "modern" Brazil. In order to carry out the research we work with different types of files such as: personal archives documents, periodicals of the Brazilian Digital Library and the collection of the Center for Institutional Memory of the Institute of Education - CEMI.
\end{abstract}

Keywords: Educational audiovisual. Teacher training. Educational television.

\title{
Resumen
}

El objetivo del artículo es analizar el circuito de Televisión Educativa del Instituto de Educación del Estado de Guanabara, destacando la centralidad del profesor como productor de contenido para televisión, actuante en la concreción de un ideal de audiovisual educativo que atienda las expectativas de la sociedad en el ámbito cultural Político y económico. La formación para la televisión educativa ha señalado caminos para la creación de una didáctica propia para los audiovisuales educativos atender a una creciente demanda de escolarización que ocurrió con la expansión de la educación en consonancia con ideales democráticos liberales para la construcción de un Brasil "moderno". Para la realización de la investigación trabajamos con diferentes tipos de archivos como: documentos de archivos personales, periódicos de la Hemeroteca Digital Brasileña y el acervo del Centro de Memoria Institucional del Instituto de Educación - CEMI.

Palabras clave: Audiovisual educativo. Formación de profesores. Televisión educativa. 


\section{Introdução}

A criação de um formato de audiovisual educativo e atraente, capaz de conquistar grandes audiências com conteúdo de qualidade cultural e intelectual, além de disponibilizar serviços como a inserção do cidadão no mundo letrado pela alfabetização foi o projeto de professores do Instituto de Educação do Estado da Guanabara no final da década de 1960, que fomentaram o debate sobre o uso da televisão com propósitos educativos. O objetivo do artigo é analisar o circuito de Televisão Educativa do Instituto de Educação do Estado da Guanabara, destacando a centralidade do professor como produtor de conteúdo para televisão e também na concretização de um ideal de audiovisual educativo que atendesse as expectativas da sociedade no âmbito cultural, político e econômico.

O trabalho a seguir é um recorte do estudo que resultou na tese "Pioneiros $d \boldsymbol{a}$ Teleducação na Guanabara: A Televisão Educativa na perspectiva das experiências pioneiras de teleducação e formação de professores e profissionais do Instituto de Educação do Estado da Guanabara e da Fundação Centro Brasileiro de Televisão Educativa (1960 - 1975)"”. Para a realização da pesquisa trabalhamos com diferentes tipos de arquivos como: documentos de arquivos pessoais de Gilson Amado e Lourival Marques, utilização do acervo da Hemeroteca Digital Brasileira ${ }^{2}$ para a consulta de periódicos veiculados durante os anos de 1960 até 1975, documentos do Centro de Memória Institucional do Instituto de Educação - CEMI ${ }^{3}$, organizado pela professora Heloisa Helena Meirelles dos Santos, além de entrevistas e artigos publicados na Revista Brasileira de Estudos Pedagógicos durante o período do Estado da Guanabara. Esses artigos foram importantes porque registraram o pensamento pedagógico, cultural e político que mobilizava os pesquisadores e intelectuais da época sobre os temas teleducação ou televisão educativa no Brasil e no mundo. O desafio da pesquisa foi a fragmentação do material pesquisado, principalmente porque não existem cópias dos audiovisuais educativos veiculados na época. No Brasil há pouca tradição de preservação de acervos audiovisuais por falta de interesse político e também pelos custos de manutenção. Entre os argumentos de análise da pesquisa que estamos apresentando, estão os estudos sobre História Cultural e o apagamento da memória das experiências com teleducação nesse período marcado pela ditadura civilmilitar. Existem poucas pesquisas sobre televisão educativa, lacunas que precisam ser revisitadas para a ampliação dos estudos em história da educação e mídias.

A primeira emissora de televisão brasileira foi a TV Tupi, inaugurada no dia 18 de setembro de 1950, em São Paulo, como parte integrante dos Diários Associados ${ }^{4}$, grupo de empresas de comunicação dirigido por Assis Chateaubriand. Os primeiros aparelhos de televisão eram muito caros, importados e a transmissão de programas era limitada e ao vivo. A televisão chegou ao Brasil no período em que o rádio era o veículo de comunicação mais popular do país, com abrangência quase nacional, alcançando famílias nos centros urbanos e nas áreas rurais. Diferente do rádio, que inicialmente pautou a programação com base na cultura e na educação, a TV nasceu com propósitos comerciais, com o objetivo de ampliar o consumo de bens e de serviços pela via da informação de notícias do cotidiano e do entretenimento.

Entretanto, alguns educadores brasileiros identificavam o potencial educativo da televisão, tendo como parâmetro a experiência da rede BBC que se consolidava como veículo estatal e educativo na Europa. Nos Estados Unidos, a criação da primeira emissora de TV educativa, a WOI-TV do Iowa State College, que começou a funcionar regularmente em fevereiro

\footnotetext{
${ }^{2}$ http://memoria.bn.br/

${ }^{3}$ http://cemiiserj.blogspot.com.br/

${ }^{4}$ Os Diários Associados eram estruturados por várias empresas de comunicação, formando um conglomerado jornalístico bastante influente. No período em que a TV foi inaugurada o grupo era detinha o controle de veículos de comunicação como o jornal O Jornal (RJ), a revista $O$ Cruzeiro, o jornal Última Hora, o jornal Diário da Noite (SP), o estúdio de cinema Tupã e as rádios Tupi, Difusora e Record.
} 
de 1950, também foi alvo do interesse de educadores no Brasil porque começou desenvolvendo uma programação direcionada ao ensino de jovens e adultos tomando como desafio a produção de conteúdo educativo, porém, atraentes e divertidos. A produção de audiovisuais educativos não era uma novidade porque a Universidade Americana de Washington D.C produzia programas educativos que eram exibidos em emissora comerciais, sinalizando também a possibilidade de parcerias com entre o Estado e as empresas de telecomunicações.

O potencial educativo da radiodifusão sempre interessou o governo brasileiro e por isso foi criada uma legislação que garantisse a autoridade do Estado sobre as atividades educativas nos veículos de comunicação de massa como rádio e televisão. No decreto ${ }^{\circ} 20.047$, de 27 de maio de $1931^{5}$, ficava clara a intenção de controle do conteúdo e da fiscalização da radiodifusão em todo o território nacional. Neste período não existia televisão no país, mas ela já era vista como veículo estratégico para a comunicação com as massas.

\section{A Televisão Educativa no Estado da Guanabara}

A TV educativa no Estado da Guanabara começou a ser concretizada nos anos iniciais da década de 1960. O Brasil vivia um período de industrialização acelerada e de crescimento populacional nas áreas urbanas. E o Estado da Guanabara estava no auge das transformações urbanas realizadas no governo de Carlos Lacerda. Foi um período de mudanças, sobretudo no setor educacional com a construção de escolas e o aumento do número de vagas na rede pública a partir da criação de classes de cooperação e a adoção de um sistema de rodízio de folgas semanais para professores com o objetivo de aumentar o número de turmas e de alunos.

Apesar da mudança da capital para Brasília, o Estado da Guanabara detinha prestígio necessário para garantir uma concentração de investimentos na região. O desenvolvimento local demandou maior necessidade de mão de obra especializada. A especialização era principalmente a alfabetização do trabalhador e a conclusão do ensino primário. Para suprir essa necessidade o governo Lacerda participou de convênios entre o MEC e a Agency for Internacional Development (AID) para assistência técnica e cooperação financeira internacional para a organização do sistema educacional no Brasil. Acordos que ficaram conhecidos como MEC-Usaid. A assistência técnica oferecida por esses acordos apontava a necessidade de adequar o sistema educacional ao modelo econômico e cultural ${ }^{6}$ previsto para países de Terceiro Mundo como o Brasil. O Estado da

\footnotetext{
${ }^{5}$ Decreto n$^{\circ}$ 20.047, de 27 de Maio de 1931 Regula a execução dos serviços de radiocomunicações no território nacional O Chefe do Governo Provisório da República dos Estados Unidos do Brasil, usando da atribuição que lhe conferem os artigos $1^{\circ}$ e $4^{\circ}$ do decreto n. 19.398, de 11 de novembro de 1930, decreta:

Art. $1^{\circ}$ Os serviços de radiocomunicação no território, nas águas territoriais e no espaço aéreo nacionais são de exclusiva competência da União.

Art. $2^{\circ}$ Para os efeitos deste decreto, constituem serviços da radiocomunicação, a radiotelegrafia, a radiotelefonia, a radiofotografia, a radiotelevisão, e quaisquer outras utilizações de radioeletricidade, para a transmissão ou recepção, sem fio, de escritos, sinais, imagens ou sons de qualquer natureza por meio de ondas hertzianas.

Art. 12. O serviço de radiodifusão é considerado de interesse nacional e de finalidade educacional.

$\S 1^{\circ}$ O Governo da União promoverá a unificação dos serviços de radiodifusão, no sentido de constituir uma rede nacional que atenda aos objetivos de tais serviços.

$\S 2^{\circ}$ As estações da rede nacional de radiodifusão poderão ser instaladas e trafegadas, mediante concessão, por sociedades civis ou empresas brasileiras idôneas, ou pela própria União, obedecendo a todas as exigências educacionais e técnicas que forem estabelecidas pelo Governo Federal.

$\S 3^{\circ}$ A orientação educacional das estações da rede nacional de radiodifusão caberá ao Ministério da Educação e Saúde Pública e a sua fiscalização técnica competirá ao Ministério da Viação e Obras Públicas.

${ }^{6}$ Um dos aspectos que atualmente mais avultam nas definições dos rumos e das estratégias de desenvolvimento das sociedades periféricas é o tipo de atuação que sobre estas vêm exercendo as agências internacionais de cooperação, pertençam ou não à Organização das Nações Unidas. É possível identificar, na maioria dessas agências do mundo capitalista, não só os aspectos ideológicos, mas também objetivos e formas de atuação semelhantes nos países de Terceiro Mundo. (...) Em todas é possível identificar um determinado conceito de subdesenvolvimento que o define de forma insuficiente, parcial, na maioria dos casos partindo de pressupostos
} 
Guanabara recebeu recursos para um levantamento da situação escolar ${ }^{7}$, sinalizando as deficiências da rede de ensino e apontando possíveis caminhos para solução das questões. Contudo, o plano não se concretizou em toda rede e representou apenas uma propaganda para a gestão Lacerda, promovendo sua imagem no cenário internacional.

A criação da televisão educativa no Estado da Guanabara estava relacionada à política de ampliação da escolaridade e também à pressão de órgãos internacionais que investiam na educação e na utilização do rádio e da televisão como fundamentais para a formação de sociedades cujos ideais democráticos estivessem alinhados às práticas econômicas do sistema capitalista. Era uma concepção de educação a serviço do desenvolvimento das nações pela industrialização e pelo consumo, gerando maior competição pelos postos de trabalho com melhor remuneração. A concepção de TV educativa no Brasil foi elaborada se apropriando de algumas dessas idéias, como assinala o artigo de Maria Terezinha Tourinho Saraiva, assessora do Ministério do Planejamento e Coordenação Econômica, no setor de Educação.

Embora em quase todo mundo a escola seja a base exclusiva para a solução do problema educacional, no Brasil a conjuntura é diferente.

A par do contingente que anualmente bate às portas da escola, há milhões de brasileiros que ultrapassam a idade escolar e que precisam da educação sob imperativos de sobrevivência ou de apelos de ascensão social. (...) $\mathrm{O}$ mundo moderno está assistindo à maior das revoluções que jamais envolveu o homem - a luta que a maioria das sociedades humanas trava, em busca de melhores condições materiais de existência. E todos sabem que a arma decisiva para ganhar essa batalha é a educação.

É urgente, pois, tornar a educação realmente acessível a todos. É preciso democratizá-la. Daí a necessidade de preparar o nosso sistema de modo a atender a todos. Mas não se esquecer a realidade brasileira - existem centenas de milhares de indivíduos, talvez milhões, que aprenderam sozinhos ao longo da vida. Já ultrapassaram a idade para o ingresso no sistema formal, mas precisam e têm direito à educação. Se não podemos ministrar pelos meios tradicionais, temos que nos valer de outros recursos que permitam levá-la a todos. (SARAIVA, 1969, p. 266 e 267)

As peculiaridades da educação brasileira no que se refere às diferenças sociais, culturais e econômicas das pessoas que tinham direito à escolarização se refletiram também no modo de estruturação de um modelo eficaz de teleducação para o aluno telespectador. A pesquisa sobre teleducação nos revelou diferentes modelos de televisão educativa: TV Utilitária, TV Pública, TV Funcional, TV Cultural, TV Didática, TV Escola e TV Instrutiva. Porém, tais modelos não formam um sistema de classificação preciso, mas mostram a diversidade de temas e objetivos que o audiovisual educativo podia oferecer aos seus consumidores, visando atender as diferentes demandas de audiências. Além disso, os sistemas de TV educativa funcionavam em duas modalidades: Circuito Fechado ou Ensino a Distancia. No circuito fechado as transmissões eram feitas por cabos para um local especifico, a área de abrangência era pequena,

\footnotetext{
que o consideram como uma fase anterior ao desenvolvimento, estando portanto, os países nele imersos apenas “em atraso" em relação aos países desenvolvidos ( ROMANELLI, 2012, p.204)

${ }^{7} \mathrm{O}$ modelo administrativo de Lacerda elegeu como prioridades a transformação do espaço urbano e a educação do Estado da Guanabara. Contudo a trajetória política dele se configura pela contradição. Ao mesmo tempo em que comandou a construção de dezenas de escolas públicas no Estado da Guanabara, Lacerda foi também defensor da privatização da educação. Se apropriando dos ideais democráticos da Constituição de 1946, Lacerda criticou a política educacional no Brasil porque ela seguia um modelo que determinava pela formação escolar quem seriam os trabalhadores manuais e os trabalhadores intelectuais. Ele condenava a educação totalitária e aristocrática do Estado coincidindo com os renovadores da educação que repudiavam o dualismo reproduzido no ensino.
} 
às vezes restrita a apenas uma instituição. Na categoria ensino à distância a transmissão era feita por radioeletricidade com capacidade de transmissão do sinal a longa distância.

Uns poucos educadores e pessoas ligadas à educação começaram a Televisão Educativa no Brasil. Começaram-na do nada, ou quase nada que era a Teleivisão Comercial. No alvorecer daquela, quando poucos cortavam, dirigiam e operavam a televisão, vultos como Fernando Tude de Souza, Mario Paulo de Brito, Marília Antunes Alves, Alfredina de Paiva e Souza e Gilson Amado, entre outros, começaram a preocuparse com o uso da TV na educação.

Alguns dessês pioneiros aprenderam o instrumento "carregando-o" penosamente, quando cada conhecimento era um repetir de ensaio e êrro, até o limiar de uma técnica que possibilitasse a realização de um programa realmente educativo. Isso, não porque não soubessem como educar, mas porque a educação se deveria fazer através de um instrumento totalmente nôvo, até ai apenas nas mãos de técnicos ou simples operadores. (ASSUNÇÃO, 1969, p. 278)

Entre as primeiras experiências do uso da televisão na educação formal, destacamos o trabalho da Fundação João Baptista do Amaral (TV-Rio) ${ }^{8}$ instituída em 18 de abril de 1961, registrada como pessoas jurídica em 2 de outubro de 1961 e reconhecida pelo MEC em 21 de novembro do mesmo ano. A Fundação foi responsável pela produção de um curso destinado à alfabetização de adultos que ficou no ar até o ano de 1965 sob a direção da professora Alfredina de Paiva e Souza. O nome do programa era O Futuro Começa Hoje ${ }^{9}$, com narração de Luís Jatobá $^{10}$. Foi uma experiência pioneira de TV direcionada à cultura e educação, com apoio de Dom Helder Câmara. Foram 216 programas, para 72 semanas, com três programas por semana. O curso atingiu mais de 5 mil alunos em 105 núcleos de recepção de tele-alunos.

Em 1962, Gilson Amado ocupou o horário das 22h30min, da TV Continental com programa chamado Mesas Redondas, no qual difundiu a idéia da Universidade de Cultura Popular cujo objetivo era atender milhares de brasileiros maiores de 16 anos que estavam fora da escola dando-lhes oportunidade de começar ou retornar aos estudos. Amado definia a idéia como "uma universidade sem paredes" porque estaria onde o aluno estivesse. A Universidade de Cultura Popular foi reconhecida como de utilidade pública em 1967, ela produziu cursos de Artigo 99 e de Admissão ao Ginásio em convênio com a Secretaria do Estado da Guanabara, além de cursos de cultura geral. Foram produzidos seis cursos compreendidos como de cultura geral com os seguintes títulos: Educação Familiar, Aprenda a Cuidar de seu Filho, Escola de Pais, Aprenda a ver Pintura, História da Formação Nacional e História da Liberdade na América.

O marco institucional da TV Educativa do Brasil em âmbito nacional foi a criação do Centro Brasileiro de TV Educativa, pela lei $\mathrm{n}^{\circ}$ 5.198, de 3 de janeiro de 1967, sob forma de fundação ${ }^{11}$. O nome Fundação Centro Brasileiro de Televisão Educativa foi formalizado no

\footnotetext{
${ }^{8}$ A Fundação João Baptista do Amaral ficou no ar até o ano de 1977.

${ }^{9}$ Fonte: A Noite -28/07/71; Jornal do Brasil -23/09/61; Correio da Manhã -02/09/61. O programa O Futuro Começa Hoje, também era conhecido como TV Escola e foi exibido em rede em outros estados: Minas Gerais, São Paulo, Espírito Santo, Brasília, Guanabara e parte de Goiás. (Diário de Notícias - semana de 06 a 12/08/61).

${ }^{10}$ Luís Jatobá foi jornalista e locutor, trabalhou na A Hora do Brasil, no Repórter Esso e outros.

${ }^{11}$ Fundação Pública - a entidade dotada de personalidade jurídica de direito privado, sem fins lucrativos, criada em virtude de autorização legislativa, para o desenvolvimento de atividades que não exijam execução por órgãos ou entidades de direito público, com autonomia administrativa, patrimônio próprio gerido pelos respectivos órgãos de direção, e funcionamento custeado por recursos da União e de outras fontes. Fonte: http://www2.camara.leg.br/legin/fed/declei/19601969/decreto-lei-200-25-fevereiro-1967-376033-norma-pe.html.
} 
primeiro estatuto da entidade com o objetivo de facilitar sua ação jurídica ${ }^{12}$. O Presidente da República, Humberto Castello Branco sancionou a lei $\mathrm{n}^{\circ} 5.198$ que estabelecia, no artigo $3^{\circ}$, que a finalidade do centro seria a produção, aquisição e distribuição de material audiovisual destinado à radiodifusão educativa. A lei ainda autorizou o poder executivo a abrir crédito especial, no valor de um bilhão de cruzeiros, para o Ministério de Educação e Cultura, que doaria o valor a FCBTVE para a compra de imóveis, títulos, equipamentos técnicos e despesas de instalações. Os equipamentos e materiais educativos importados pela Fundação seriam isentos de impostos de importação e consumo, e também da taxa de despacho aduaneira.

A FCBTVE foi estruturada como o órgão capaz de integrar a emissoras educativas já existentes, promover pesquisas e intercâmbio com outros países para aprimorar as TVs educativas brasileiras. A FCBTVE instalou um sistema de circuito fechado de televisão que dispunha de um estúdio de $14 \mathrm{~m}^{2}$ destinado para o treinamento de pessoal docente, técnicos e de produção, além de funcionar como laboratório experimental para realização de programas educativos. No mesmo ano em que entrou em vigor, o professor Manoel Jairo Bezerra formulou um curso para professores leigos. Havia necessidade e interesse em formar profissionais qualificados para atuar com tele didática, ou seja, capazes de operar com uma linguagem audiovisual com objetivos educacionais específicos; e adequada às especificidades do público brasileiro interessado em aprender pela televisão. Os objetivos educacionais poderiam estar alinhados à educação formal com certificação de ensino ou a educação não formal com conteúdo considerado útil para o dia-a-dia ou para melhorar a formação cidadã e política.

Apesar da expectativa gerada com a criação da FCBTVE, a programação educativa não obteve o apoio esperado, principalmente das emissoras comerciais, obrigadas por lei, a exibirem conteúdos educativos e culturais na grade de programação. Na prática, o conteúdo visto como cultural obteve mais espaço pela maior facilidade de adequação aos conteúdos de educação não formal. A programação direcionada à educação formal obtinha bons índices de audiência, porém o aparato estrutural composto por material didático, telesalas, registro dos alunos, exame de qualificação para certificação e treinamento de pessoal exigiam investimento maior.

O entendimento de TV educativa do final dos anos 1960 demandava maior participação de professores na condução da programação. O professor deveria assimilar o trabalho dos técnicos e operadores de televisão para depois traduzirem nessa nova linguagem (audiovisual) para a mensagem educativa. Já neste período, a aula televisada era criticada e vista como um desserviço da TV educativa porque não se apropriava da linguagem televisiva.

\section{O pioneirismo do Instituto de Educação do Estado da Guanabara}

A formação para a televisão educativa sinalizou caminhos para a criação de uma didática própria para produtos audiovisuais educativos direcionados ao perfil do telespectador brasileiro. Havia uma demanda crescente de escolarização que ocorreu com a expansão da educação em consonância com ideais democráticos liberais para a construção de um Brasil "moderno", em desenvolvimento. Romper as mazelas do subdesenvolvimento do país era o projeto político e ideológico do período que denominava a educação como a estratégia salvadora da nação.

A educação vista como fator de mudança social e de desenvolvimento da nação rompe com a estabilidade criada no dualismo do ensino que determinava o tipo de educação para os diferentes grupos socioeconômicos. A educação primária era considerada suficiente para as camadas mais pobres que eram direcionadas às escolas profissionalizantes, do outro lado as elites, visando entrar no ensino superior, seguiam na educação secundária. Não existia tanto interesse pela escolarização com certificação de ensino nas camadas mais pobres. Com o desenvolvimento industrial do país a demanda potencial - correspondente ao número de

${ }^{12}$ Em 03/05/1967 a entidade adquiriu personalidade jurídica, com inscrição em cartório do seu primeiro estatuto. A inscrição foi o sob o n ${ }^{\circ} 16972$, do livro A-8. 
pessoas em idade de escolarização fora da escola ou analfabeta - se transforma em demanda efetiva, ou seja, a pressão social por ensino em todas as classes e regiões do país obriga o Estado a investir em uma educação ao alcance de todos. Entre os recursos utilizados, a teleducação se destacou como possibilidade de democratização do ensino.

Por mais que as escolas se multipliquem, no empenho estatal de assegurar a todos o direito ao ensino, mais do que as escolas, cresce a população em idade correspondente. As circunstâncias induzem a um apelo às instituições culturais para que elas cumpram uma parcela ponderável em matéria de educação. (...) Uma nova linguagem paraescolar começa a afirmar-se como fruto dos novos meios de comunicação, em socorro da escola, para o ideal de atendimento de todos (KELLY, 1969 p. 94-95)

Segundo Romanelli (2012) a demanda social por educação foi fator-chave para a expansão do ensino no país, mas não criou mudanças profundas na situação escolar. As propostas de ampliação da educação por parte do governo eram emergenciais e pouco consistentes para ecoarem uma transformação educacional de fato capaz de equilibrar a oferta de ensino entre ricos e pobres. A teleducação surgiu como proposta viável para alfabetização e conclusão do ensino primário, mas contava com pouco investimento do governo.

\section{A TVE do Instituto de Educação do Estado da Guanabara}

A primeira experiência com televisão educativa no Instituto de Educação do Estado da Guanabara, utilizando uma estrutura completa de equipamentos para televisão, em circuito fechado, ocorreu em 1967. Os equipamentos foram instalados durante o $1^{\circ}$ Congresso Brasileiro de Audiovisuais realizado entre os dias 23 e 29 de julho de $1967^{13}$, patrocinado pelo MEC e pelo governo da Guanabara e organizado pela Associação Brasileira de Educação. A professora Alfredina de Paiva e Souza foi coordenadora geral do congresso que reuniu cerca de dois mil professores de todo o país. O congresso tinha o objetivo de discutir as múltiplas possibilidades de inserção do audiovisual nos diferentes níveis de ensino.

Desta forma, o Instituto de Educação apropriou-se da tarefa de criar uma formatação para o audiovisual educativo e inaugurou o $1^{\circ}$ Centro Experimental de Produção e Treinamento de Pessoal para a Televisão Educativa, em 1967. No anuário de 1968 da instituição, há o registro da aprovação do Conselho Técnico do Instituto de Educação para a compra de um equipamento de televisão educativa no valor de cinqüienta mil cruzeiros, que deveria ser pago em dois anos e ser instalado definitivamente até 31 de dezembro de 1968. A aquisição dos equipamentos consolidou a participação do Instituto de Educação da Guanabara no planejamento da televisão educativa no país.

Que papeis pode ou deve desempenhar o professor na TVE? Ainda não se fêz estudo minucioso a respeito, mas do extremo da não existência de educador qualificado num programa chamado educativo até uma equipe composta tôda ela de professôres, tanto mais certos estaremos quanto mais próximos desta posição estivermos.

Que extraordinário operador de audição seria um professor de música; que magnífico cortador na encenação de uma peça teatral seria um

\footnotetext{
${ }^{13} \mathrm{O}$ congresso foi amplamente divulgado na mídia impressa do período. Foram mais de 30 reportagens e notas publicadas contabilizadas em três periódicos: Correio da Manhã, Diário de Notícias e Jornal do Brasil. Nos impressos o objetivo do congresso foi definido como uma tomada de decisão dos educadores brasileiros sobre o crescimento dos audiovisuais.
} 
professor de arte dramática; que perfeita apresentadora seria uma professora de canto desde que, todos, evidentemente, se tivessem preparado para essa atuação. Mas, acima de tais funções, que não seriam desempenhadas obrigatoriamente por professores, parece-nos necessário que sejam realmente professôres o diretor da emissora, os diretores de programação e de produção, os produtores, os diretores e o apresentador. (ASSUNÇÃO, 1969, p.279)

Inicialmente a televisão educativa do Instituto de Educação funcionava em circuito restrito e com pretensões locais, porém ampliou e se integrou a proposta teleducação da FCBTVE defendendo a necessidade de iniciativas e investimentos em produtos audiovisuais exclusivamente educativos. As professoras Alfredina de Paiva e Souza e Judite Brito de Paiva e Souza coordenaram o projeto que previa uma série de cursos de formação e treinamento em televisão educativa.

Durante os anos 1970 e 1971, o Instituto de Educação fez convenio para transmissão de programas educacionais com uma emissora comercial de TV do Rio de Janeiro, a TV Continental, Canal 9. A programação era exibida em horário nobre, das 19 às 21 horas de segunda a sexta. O centro de televisão do Instituto tinha dois estúdios com equipamentos profissionais e uma sala de controle técnico e os cursos oferecidos receberam professores de diferentes partes do Brasil. A parceria com a FCBTVE promoveu cursos que não eram restritos aos professores e atraíram profissionais de diferentes ramos interessados em aprender ou se especializar em audiovisuais educativos.

Em 1969, a FCBTVE desenvolveu quatro cursos de formação básica em TVE que receberam mais de 150 alunos de diferentes estados do país. Essas experiências iniciaram a formação de um acervo de material audiovisual educativo produzido no Brasil e estimularam a criação de um projeto com conteúdo correspondente às séries iniciais do curso primário. $\mathrm{O}$ projeto mais tarde se tornou a telenovela educativa João da Silva.

\section{Audiovisual Educativo: professores criadores e produtores de conteúdo para TV}

A televisão educativa do Instituto de Educação do Estado da Guanabara tinha quatro objetivos fundamentais $^{14}$ : preparação e treinamento de pessoal para a televisão educativa, atendendo a expectativa do governo em aproveitar o potencial dos veículos de comunicação de massa na educação; uso da televisão como auxiliar no trabalho dos professores nas atividades de sala de aula em todos os níveis de ensino, desde o jardim de infância ao Curso Superior de Formação de Professores para o Ensino Normal (CFPEN); ampliação da área de influência pedagógica do Instituto, dando lhe destaque na atualização das técnicas de didática, na de divulgação científica e cultural, na orientação vocacional e na promoção socioeconômica e cultural do povo; e participação direta na reformulação dos padrões de televisão comercial da Guanabara, exercendo influência esclarecida e bem orientada na elaboração de programas culturais e artísticos das emissoras comerciais. Existia o interesse do Instituto de Educação do Estado da Guanabara em assumir a função de protagonista na análise e na crítica do conteúdo televisivo definido como cultural e educativo pelos produtores das emissoras comerciais. O objetivo era legitimar a importância da centralidade de um profissional de educação no planejamento e produção de audiovisuais educativos, defendendo a presença do professor em todas as etapas de produção dos programas educativos. A abrangência da televisão e o poder de conquistar grandes audiências foi um indicativo da necessidade de maior controle da qualidade do que era exibido, principalmente da programação como cultural, enquadrada no quesito da educação não formal.

\footnotetext{
${ }^{14}$ Informações retiradas do anuário de 1968 do Instituto de Educação.
} 
Entenda-se por televisão educativa (Educational TV) não apenas a televisão didática, escolar (Instructional TV), que constituirá o principal objeto de nosso exame, mas aquela que além das aulas formais, apresenta programações de teatro, música, pintura, documentários, eventos de interesse geral etc., visando a um melhor status do indivíduo. À sua formação intelectual, cultural e moral, e ao progresso da comunidade.

A televisão a serviço da educação representa uma adaptação, principalmente da escola, às necessidades e recursos do mundo atual. (PAIVA E SOUZA, 1969, p. 286)

Judith Brito de Paiva e Souza (1969), uma das coordenadoras do curso de televisão educativa do Instituto de Educação destacou algumas vantagens da utilização da televisão educativa como: a televisão ampliava a atuação dos melhores mestres pondo suas aulas ao alcance de todos os alunos alcançados pelo raio de ação de uma emissora; a televisão podia veicular recursos inacessíveis à maioria das escolas com o uso do audiovisual potencializando o poder das imagens em movimento na aceleração e eficiência da aprendizagem; a televisão permitia a visualização do detalhe, com o recurso do "close", por todos os alunos.

As palavras da coordenadora contrastavam com a realidade da TV educativa que existia no Brasil da época porque as produções se resumiam a aulas televisionadas, geralmente direcionadas aos cursos supletivos. A crítica era direcionada à impossibilidade de a televisão substituir a comunicação direta entre professor e aluno.

O interesse por uma TV educativa de melhor qualidade, que não se limitasse à substituição do professor pelo monitor de TV para resolver problemas educacionais como: falta de professores, falta de vagas nas instituições escolares e altos índices de analfabetismo, iniciou o debate sobre a necessidade de formação de professores para atender a demanda especifica de educação pela televisão.

É verdade que qualquer mensagem de conteúdo educativo, ainda que mal apresentada como programa de televisão, será mais proveitosa que algumas comerciais de conteúdo indiscutivelmente deseducativo e, lamentávelmente, de fabulosas audiências. Mas, se nós educadores, conhecemos o caminho certo, porque preferiremos o atalho medíocre e tão pouco fértil da rotina? Por que incidiremos em erros que somo capazes de criticar, aquêles mesmos erros dos que abriram caminhos ou dos que se acomodam a situações mais fáceis? E aqui cabe mais um lugar-comum: uma aula por televisão não é o simples televisionamento de uma aula de classe. (...) A alguns poderão parecer de somenos importância estas observações. Mas lembramos que qualquer ator de televisão recebe instruções que o tornam mais apto para o seu trabalho. Já existe mesmo uma literatura sôbre o assunto.

Julgamos oportunas essas considerações a fim de fundamentarmos a tese da necessidade de especializar-se o professor que se destina às atividades da televisão educativa. E diremos mais, até o setor de operação deve ser preparado para a finalidade específica do trabalho em educação. Um tratamento artístico inadequado, por exemplo, pode ter efeitos negativos quanto aos objetivos didáticos da mensagem. (PAIVA E SOUZA, 1969, p. 287 -288)

A partir destas ideias, foi criado o Primeiro Centro de Produção e Treinamento de Pessoal para a Televisão Educativa no Brasil do Instituto de Educação do Estado da Guanabara. Logo após, 
foi feito o primeiro convênio com FCBTVE, ampliando, de fato, a influência do Instituto em âmbito nacional. Os equipamentos eram de excelente qualidade, mas os estúdios ainda não estavam completos. Essa estrutura foi utilizada para a realização do $1^{\circ}$ Curso de Preparação para a Televisão Educativa, que recebeu inicialmente 106 professores da rede oficial de ensino do Estado da Guanabara $^{15}$. Foram duas turmas e o conteúdo do curso foi exposto em duas etapas. A primeira foi elaborada com palestras e demonstrações práticas sobre os seguintes assuntos ${ }^{16}$ :

- Televisão Educativa: problemas de hoje, TVE no mundo e a experiência brasileira;

- Origem e situação atual da televisão: teatro, rádio e cinema em face da televisão; características específicas da televisão, programações de televisão, estações e redes;

- Elementos de eletrônica: ondas eletromagnéticas, a imagem, a cor, o som em TV;

- Como opera a televisão: estrutura de uma emissora, o estúdio, a iluminação, a sala de cortes, os serviços complementares;

- Produção de programas: a equipe de TV, o setor de artes, operação da câmara, apresentação de programa, importância da fala, técnica de preparação de roteiros;

- Planejamento da Televisão Educativa: os programas de televisão educativa, os centros de produção, a rede de recepção.

Esses temas foram desenvolvidos pelos alunos e o resultado das aulas práticas foi a roteirização, produção e realização de programas experimentais que visavam imprimir modelos de audiovisuais educativos para a audiência brasileira. As áreas de conhecimentos escolhidas pelos alunos foram:

- Ciência - Luzé Vida

- Música - Música no curso primário

- Sociologia - Liderança

- Psicologia - Causas sensoriais do mau aprendizado

- Higiene - Alimentação

- Educação Comunitária - SOS! Professora (noções de primeiros socorros)

- Genética - Os cromossomos

- História - Ciclo do ouro

- Geografia - O universo esse desconhecido

- Ciências Sociais - Relações humanas na classe

Oito desses programas foram gravados na TV Continental e exibidos em circuito aberto para os telespectadores da Guanabara. Mais tarde, seis deles se tornaram cópias em fitas magnéticas de $1 / 2$ polegada e passaram a fazer parte de uma coleção de programas educativos ${ }^{17}$, com títulos nacionais e internacionais, mantida de pelo Instituto de Educação. Nessa fase inicial, os primeiros professores do curso foram: Alfredina de Paiva e Souza, diretora da Fundação João Batista do Amaral (FJBA); Judith de Paiva e Souza, assessora da FJBA, Allan Ferreira de Lima Oliva, do setor de comunicações da Embaixada Britânica; Gastão Roberto Coaracy, do setor de audiovisuais da USAID; John Vince, chefe do serviço de televisão da Embaixada Americana; e Syla Chaves, do departamento de comunicação da Fundação Getúlio Vargas. Todos os professores do curso estavam inseridos em projetos que tinham como meta a formatação de um perfil de teleducação no Brasil,

${ }^{15} \mathrm{O}$ diretor geral do Instituto de Educação do Estado da Guanabara, José Teixeira d Assumpção, e a diretora da Escola Normal Ignácio Azevedo do Amaral, Samira Khury de Andrade, participaram como alunos da primeira turma formada para o curso de Preparação para Televisão Educativa.

${ }^{16}$ Informações retiradas do anuário da Instituição de 1968.

${ }^{17}$ Entre os títulos conservados: França- Ensino da Língua Francesa; Itália - Alfabetização de Adultos; Brasil - Alfabetização de Adultos: TV Escola FJBA. 
que neste momento, apresentava-se sob forte influência do capital internacional que contribuía com convênios para compra de equipamentos, com intercâmbio de profissionais e também com a propagação de sugestões sobre alfabetização que atendesse aos interesses do mercado internacional e favorecesse o projeto de desenvolvimento social da ditadura civil-militar que ocupava o governo. Os meios de comunicação de massa, principalmente os mais populares, como rádio e televisão, reproduzem em alguns momentos o controle social. "Eles podem nesse sentido, concorrerem de forma ponderável para disciplinar atitudes e mentalidades" (LAGO, 1971, p.53). Assim, muitas vezes, foram postos a serviço de propósitos políticos, ideológicos e econômicos. O uso da televisão como veículo disponível também para a educação, não era apenas uma solução para os governos, mas era também uma aspiração social. A popularidade da televisão e as possibilidades técnicas do audiovisual, aliada à crítica sobre a baixa qualidade da programação das emissoras comerciais, propiciou o debate em defesa de programas mais educativos e instrutivos. Isso, de certa maneira, movimentou os profissionais da educação no sentido de reivindicar, apoiados no saber pedagógico e da didática, o pioneirismo nas experiências com teleducação.

A relevância da definição da proposta de televisão educativa praticada no Instituto de Educação parte da premissa que existem dois aspectos básicos e interligados ao formato televisivo quando nos referimos aos conteúdos educativos. O primeiro se configura em um plano geral que visa propagar conhecimentos que promovem práticas sociais, culturais e econômicas, e é direcionado às grandes audiências, tem apelo comercial, busca também o entretenimento, mas foca em assuntos e temas importantes para o desenvolvimento humano e social das audiências. Já o segundo se estabelece pela necessidade de um planejamento que assegure a intencionalidade do caráter instrutivo do conteúdo apresentado na programação. Pode-se alcançar uma grande audiência, mas tem objetivos sólidos em relação a determinados públicos, como por exemplo, o formado por telealunos dos cursos de alfabetização e supletivo. A televisão educativa não estaria a serviço somente das massas de telespectadores porque deveria ter parte de sua programação direcionada a um público-alvo específico formado indispensavelmente por telealunos. A televisão educativa deveria ser gerida por educadores, que com a formação adequada também seriam diretores e produtores dos conteúdos educativos.

\section{Considerações finais}

A formação pretendida no Instituto ampliava o espaço de atuação do professor que estava restrito à sala de aula. Nesta perspectiva, o professor entrava na disputa por espaço de trabalho no mercado de radiodifusão delimitando para a televisão educativa para os educadores. $\mathrm{O}$ circuito de TV educativa do Instituto funcionou como um laboratório de experiências audiovisuais com professores, profissionais de televisão, técnicos e profissionais interessados no assunto. Inicialmente o público alvo eram professores, mas em pouco tempo, outros objetivos se tornaram também prioridade como: a formação de mão de obra para o corpo técnico das TVs estatais, a formação dos próprios alunos nos diferentes níveis escolares, a definição de uma linguagem para a televisão educativa no país.

O pensamento pedagógico disseminado pelo Instituto de Educação foi o modelo seguido para a radiodifusão educativa da época, que em uma primeira análise, se apresentou como um conceito amplo de significados abrangendo as múltiplas possibilidades educativas que podiam se enquadrar na programação do rádio e da televisão. Mas posteriormente, a radiodifusão educativa foi definida seguindo algumas prerrogativas como: intencionalidade na ação formativa; adequação ao nível de audiência; inserção em um planejamento global; previsão dos efeitos a atingir; e condição para avaliar esses efeitos. Esses requisitos se relacionavam à audiência da programação educativa, que seria avaliada pela quantidade de telespectadores e pela resposta dos mesmos na promoção de uma sociedade mais escolarizada e de acordo com valores da época. Período caracterizado pela censura da ditadura civil militar e pela valorização de aspectos morais da 
sociedade e de nacionalismo. No campo pedagógico o modelo tecnicista, que considerava a eficiência do ensino como decorrente do uso correto e planejado de métodos técnicos e didáticos, servia como norte para as justificativas e avaliações dos resultados esperados. A formação desses profissionais foi organizada a partir da necessidade de se conhecer a técnica televisiva nos seus processos de produção para, assim traçar um planejamento didático e pedagógico adequado aos diferentes grupos que poderiam ser atingidos.

\section{Referências}

ASSUNÇÃO, José T. Pedagogia e Produção para a TVE. Revista Brasileira de Estudos Pedagógicos, v.52, n. 116, out./dez.,1969.

BERGAMO, Alexandre. A reconfiguração do público. In: RIBEIRO, Ana Paula; SACRAMENTO, Igor; ROXO, Marcos (Orgs.). A História da Televisão no Brasil. São Paulo: Contexto, 2010.

JAMBEIRO, Othon. A TV no Brasil do século XX. Editora da Universidade Federal da Bahia (EDUFBA), 2002.

KELLY, Celso. Política da Educação. Rio de Janeiro: Editora Reper, 1969.

LAGO, Benjamim do. Comunicação, Educação e Desenvolvimento. Rio de Janeiro: Edições Gernasa, 1971.

LEITÃO, Yacy de Andrade. Contribuições para o estudo da teledidática a partir de uma experiência de televisão educativa no Estado da Guanabara. Rio de Janeiro, 1973. 169f. Dissertação (Mestrado em Educação) - Departamento de Educação, Pontifícia Universidade Católica do Rio de Janeiro.

LOPES, Sonia de Castro. Oficina de mestres: História, memória e silêncio sobre a Escola de professores do Instituto de Educação do Rio de Janeiro (1932-1939). Rio de Janeiro: DP\&A, 2006.

SOUZA, Alfredina de Paiva e. Pedagogia e Produção dos Programas da RTV Educativa. Revista Brasileira de Estudos Pedagógicos, v.52, n. 116, out./dez., 1970.

PRIOLLI, Gabriel. A tela pequena no Brasil grande: anos 50: o patrocinador faz o show. In: LIMA, Fernando Barbosa; PRIOLLI, Gabriel; MACHADO, Arlindo. Televisão e vídeo. Rio de Janeiro: Jorge Zahar Editor, 1985.

RIBEIRO, Ana Paula Goulart; SACRAMENTO, Igor. A Renovação Estética da TV. In: RIBEIRO, Ana Paula; SACRAMENTO, Igor; ROXO, Marcos (Orgs.). História da televisão no Brasil. São Paulo: Contexto, 2010.

PAIVA E SOUZA, Judith B. de. Preparação de Professores para a TV Educativa. Revista Brasileira de Estudos Pedagógicos, v.52, n. 116, out./dez.,1970

ROMANELLI, Otaíza O. História da Educação no Brasil (1930-1973). Petropólis: Vozes, 2012. 